\title{
Clinical Evaluation of Total Abdominal Hysterectomy - A Prospective Study in a Tertiary Care Hospital
}

\section{S Akhter ${ }^{1}$, R Nazneen ${ }^{2}$}

Abstract

Total abdominal Hysterectomy are gradually rising in our country. This study has been designed to find out the common indications of abdominal hysterectomy in a tertiary care hospital,. to know the clinical characters of the patients and. 0 elucidate postoperative complication of abdominal hysterectomy.

Methodology : Cross- sectional observational study was done during 1st October 2007 to 30th September 2008. Holy Family Red Crescent Medical College Hospital (HFRCMCH). Total 100 patients were selected following enclusion \& exclusion criteria hyperposive sampling. Data were recorded before and after operation and analyzed by SPSS version 15.

Result : In the present study patients with leiomyoma of uterus was found to be the major indication of hysterectomy followed by dys functional uterine bleeding (DUB) 18.0\%, Pelvic inflammatory disease (PID) $14.0 \%$, chronic cervicitis $10.0 \%$, adenomyosis $10.0 \%$, pelvic endometriosis $6.0 \%$, cervical polyp $2.0 \%$, ovarian cysts $1.0 \%$ and chriocarcinoma 1.0\%. Mean duration of operation (hour) and hospital stay was 1.15 hours and 7.48 days respectively. Most common complication of present series was fever $20.0 \%$ followed by $13.0 \%$ had wound infection, $6.0 \%$ UTI and $2.0 \%$ wound dehiscence.

Conclusion : Hysterectomy is now the most widely performed major operation in gynaecology. Indication and post operative complications of hysterectomy varies from region to region.

Key words : Hysterectomy, Indications, complications.

\section{Introduction}

Hysterectomy is a very common gynaecological operation in which the uterus may be completely removed (total hysterectomy), partially removed preserving the cervix (sub-total hysterectomy), or may be removed with the tubes and ovaries (total hysterectomy with bilateral salpingoophorectomy).

Historically, Langen Beck performed the first abdominal hysterectomy in 1825. Porro first performed the subtotal caesarean hysterectomy successfully in1876, where Wertheim performed his first abdominal hysterectomy in 1898. Vaginal hysterectomy was performed more than 250 years prior to the first abdominal hysterectomy. Seventy percent $(70 \%)$ of hysterectomies now a day are abdominal and thirty percent (30\%) are vaginal ${ }^{1}$.

Hysterectomy is usually performed for problems including uterine fibroids, endometriosis, adenomyosis, utero vaginal prolapse, heavy or abnormal menstrual bleeding, and at least three forms of cancer (uterine, cervical, ovarian). Hysterectomy is also a surgical last resort in uncontrollable postpartum obstetrical haemorrhage.

In our country conventional abdominal and vaginal methods are traditionally performed throughout most hospitals and clinics. Very recently laparoscopic assisted hysterectomy has become available in few hospitals.

\section{Objectives}

- To know the clinical and sociodemographic characters of the patients.

- To see the postoperative complications like hemorrhage, urinary tract, wound and other system infections.

\section{Materials and Methods}

This cross sectional study was conducted in the Department of Obstetrics and Gynaecology, HFRCMCH, Dhaka from 1st October 2007 to 30th September 2008 HFRCMCH. Purposive sampling was done. Total 100 patients were selected consecutively after considering inclusion and exclusion criteria.

Any patient admitted having indication for abdominal hysterectomy in HFRCMCH were enrolled in this study. Patients unwilling to take part in the study, Septic abortion, Ruptured uterus, PPH, Ovarian Malignancy, Carcinoma Cervix were excluded from the study. After admission, written consents were taken from the patients. Clinical diagnosis was made on the basis of history and examination and necessary investigations. Peroperative findings were evaluated and diagnosis was confirmed by histopathology. All personal data were gathered. Other biological parameters were recorded. Finally data were analyzed by the SPSS package 15 (SPSS Inc, Chicago, IL, USA). The results were presented in tables and figures.

A permission to conduct this study was obtained from HFRCMCH ethical committee.

\section{Result}

Out of 100 patients, Leiomyoma of uterus (38\%) was found to be the major indication of hysterectomy followed by DUB (18.0\%) and most common in between 41-45 years of age Hysterectomy for other indications are in $3^{\text {rd }}$ decades (Table I).

Table I : Distribution of patients on indication of hysterectomy and age

\begin{tabular}{lccccc} 
Indication of & \multicolumn{2}{c}{ Percent } & \multicolumn{4}{c}{ Age in years } \\
$\begin{array}{l}\text { hysterectomy } \\
\text { Leiomyoma of }\end{array}$ & 38.0 & $\mathbf{3 4 - 4 0}$ & $\mathbf{4 1 - 4 5}$ & $\mathbf{4 6 - 5 0}$ & $\mathbf{5 1 - 5 5}$ \\
uterus & & & 22 & 8 & 2 \\
DUB & 18.0 & 4 & 7 & 4 & 3 \\
PID & 14.0 & 2 & 10 & 2 & - \\
Chronic cervicitis & 10.0 & 4 & 3 & 2 & 1 \\
Adenomyosis & 10.0 & 2 & 5 & 3 & - \\
Ovarian cysts & 1.0 & - & - & 1 & - \\
Choriocarcinoma & 1.0 & 1 & - & - & - \\
Pelvic & 6.0 & 4 & 2 & - & - \\
endometriosis & & & & & \\
Cervical polyp & 2.0 & - & - & - & - \\
Total & 100.0 & - & - & - & -
\end{tabular}


In this study most of the patients belongs to the middle socioeconomic class (56.0\%) whose monthly income is around 20,000 taka followed by $24.0 \%$ from lower socioeconomic class (monthly income less than 20,000) (Table II).

$\begin{array}{lc}\text { Table II : Patients distribution of Socioeconomic status }(\mathbf{n}=\mathbf{1 0 0}) \\ \text { Socioeconomic status } & \text { Percent } \\ \text { Upper } & 20.0 \\ \text { Middle } & 56.0 \\ \text { Lower } & 24.0 \\ \text { Total } & 100.0\end{array}$

Out of all patients maximum $63.8 \%$ had heavy menstrual flow (they had history of passage of medium sized clot during the $1^{\text {st }} 2-3$ days of menstrual cycle) followed by $31.9 \%$ average flow (4-5 pads/day) and only $4.3 \%$ had scanty flow (Table III).

\section{Table III : Distribution of the respondents by amount of menstrual flow $(n=94)$}

$\begin{array}{lc}\text { Flow } & \text { Percent } \\ \text { Scanty } & 4.3 \\ \text { Average } & 31.9 \\ \text { Heavy } & 63.8\end{array}$

Out of all patients maximum $56.0 \%$ patients had menorrhagia[ menstrual flow increased either in amount or durationcyclically], 34.0\% had Dymenorrhoea [painful menstruation] 28.0\% patients had Polymenorrhagia[.menstrual cycle <21days] (Table IV)

$\begin{array}{ll}\text { Table IV : Distribution of patients by menstrual condition } \\ \text { Menstrual condition } & \text { Percent } \\ \text { Menorrhagia } & 56.0 \\ \text { Dymenorrhoea } & 34.0 \\ \text { Polymenorrhagia } & 28.0 \\ * \text { Multiple responses } & \end{array}$

Out of all patients $6.0 \%$ had developed UTI, $20.0 \%$ had fever $13.0 \%$ had wound infection and $2.0 \%$ had wound dehiscence.

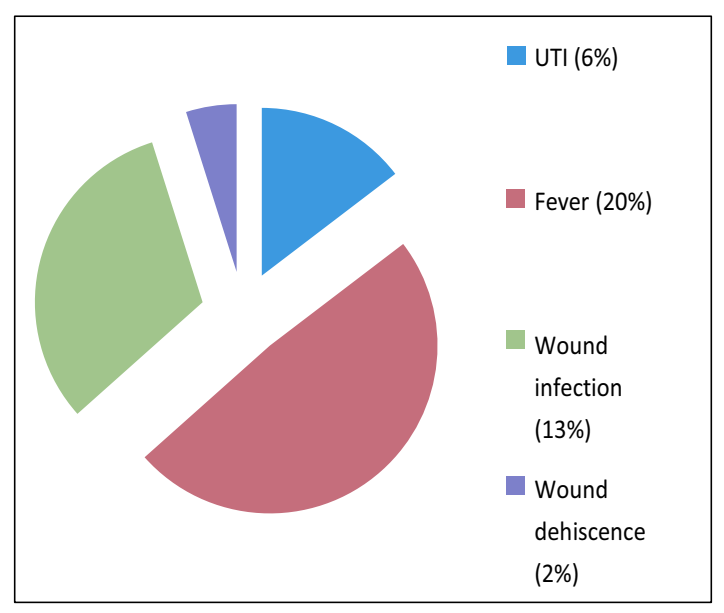

\section{Discussion}

In this study it is found that the Mean (+SD) age of the patients undergoing Hysterectomy in the present study was $43.86+4.31$ ) years.
All patients were within 36 to 55 years age range. In Amrikia et al and Dewan series age of the women who had undergone hysterectomy was within 30 to 50 years. ${ }^{2,3}$ Similar age incidence reported in other studies. ${ }^{4,5}$

In the present study maximum $56.0 \%$ patients were from middle socioeconomic status group followed by $24.0 \%$ from lower socioeconomic status and rests were from upper socioeconomic group which was consistent with the findings of Begum (2005) series. ${ }^{6}$

The number of hysterectomies performed for leiomyoma uterus was found to vary between studies. According to Amirikia ${ }^{2} 76.0 \%$ of hysterectomies were performed for leiomyoma uterus but White reported only $19.6 \%$. In our series it was $38.0 \%$. Some what similar results were reported by some other studies. ${ }^{3-5}$ Study in Faisalabad showed hysterectomy for DUB accounting for $43.3 \%$ and for fibroid was $26.7 \%$. Endometriosis accounted for $1.7 \% .^{7}$ This variation could be due to the basis of clinical diagnosis.

The complications of hysterectomy in present series were UTI $(6.0 \%)$, fever $(20.0 \%)$, wound infection $(13.0 \%)$, wound dehiscence $(2.0 \%)$. In Farhana Dewan ${ }^{3 \prime}$ s study $37.0 \%$ patiets had miscellaneous complications, in Lutfun Nahar ${ }^{4 \prime}$ s series it was $35.0 \%$.

In Farhana Dewan's series $21.0 \%$ had fever, 5.0\% had UTI. UTI was found about $5.0 \%$ in Farida Yasmin series, Lutfun Nahar series and Mahfuza Akhter series. Our result was consistent with these studies. $^{3,8,5,9}$

In Farida Yasmin's series incidence of abdominal wound infection was $5.0 \%{ }^{8}$ In Hasan Amirika's study it was only 0.14\%, Mahfuza Akhter series shows $4.0 \%$ wound infection. ${ }^{2,9}$ In our series high rate of wound infection was observed post operatively due to preexisting anaemia, malnutrition and associated diabetes mellitus.

\section{Conclusion}

Hysterectomy is now the most widely performed major operation in gynaecology. Indication of hysterectomy and post operative complications were varies from region to region.

\section{References}

1. Elliott JP et al.; Comparison of lavage or intravenous antibiotics at cesarean section; Obstet Gynecol, 1986 Jan, (1), 29-32

2. Amirikia H MD. White SC MD, "Ten years review of hysterectomy" Am J obstet. Gynaecol 2000;134,431-37.

3. Dewan F, Clinical study on 100 cases of abdominal hysterectomy (Dissertation) BCPS, Dhaka 1989.

4. Nahar L. Clinical study of abdominal hysterectomy in SSir Salimullah Medical College and Mitford Hospital Dhaka, Among the 100 cases (Dissertation) BCPS, Dhaka 2004.

5. Dicker R. C MD Lee N. C MD, "Confirmation of the pre-operative diagnosis for hysterectomy". Am J obstet. Gynaecol 2000 150; 283-7.

6. Roohi M, Qureshi S, Tahira T. Abdominal hysterectomy; Performed by postgraduate (pg) trainees. Professional Med J Dec 2007; 14(4): 685-688.

7. Begum Clinical evaluation of 104 cases abdominal hysterectomy (Dissertation) BCPS, Dhaka 2005.

8. Yasmin F Clinical study on 100 cases of abdominal hysterectomy (Dissertation) BCPS, Dhaka 1996.

9. Akter M, Clinical study on 100 cases of abdominal hysterectomy (Dissertation) BCPS, Dhaka 2004. 